\title{
Editorial
}

\section{Measurement of bronchial reactivity: a question of interpretation}

Non-specific bronchial hyperreactivity is well recognised in asthma although the underlying mechanism is poorly understood. Reproducible results can now be obtained both for exercise and for a variety of inhalation challenge tests but interpretation of the results remains controversial and poses the main challenge to work in this area. This editorial discusses some aspects of interpretation with particular reference to studies of bronchodilating and bronchoconstricting agents.

There are three main reasons for wanting to measure non-specific bronchial responsiveness. First, the expectation that further understanding of bronchial reactivity will help to unravel the cause of asthma; clearly if the cause of bronchial hyperreactivity was known our understanding of asthma would be greatly increased. Second, if a bronchial challenge test provided a useful model of asthma, drugs could be tested under reasonably controlled conditions. This approach has been of limited value since the effectiveness of a drug in blocking an acute bronchial challenge has not correlated particularly well with its effectiveness in clinical practice, as shown for example by a comparison of sodium cromoglycate with steroids. Finally, and more controversial, is the use of bronchial reactivity testing in the routine diagnosis, assessment, and management of asthma.

In man, bronchial reactivity is measured as the airway response to a standard stimulus, usually exercise or an inhalation challenge. With the latter increasing doses of stimulus allow a dose-response relationship to be obtained. This approach is analogous to measuring the change in length or tension of a strip of bronchial smooth muscle in response to a stimulus, but unfortunately, in intact man, both the stimulus and the measurement are quantified much less easily. The inhaled bronchoconstricting stimuli include histamine, methacholine, prostaglandin $F_{2} \alpha$, and cold air given with different nebulisers, nebulised volumes, particle size, and inhalation techniques, all of which affect both the site and amount of stimulus deposited in the airways. ${ }^{2}$ The amount of drug actually entering the

Address for reprint requests: Dr AE Tattersfield, Level D, Centre Block, Southampton General Hospital, Tremona Road, Southampton SO9 4XY. airways cannot normally be measured, nor, if it was known, would it necessarily reflect the pharmacological or effective stimulus dose. Studies of drugs delivered by metered aerosol have shown that $10 \%$ or less of the administered drug enters the airways. ${ }^{34}$ Nevertheless, when a subject uses an identical technique on different occasions it is reasonable to assume that the same proportion of drug will enter the airways, as long as the lungs and airways are unchanged.

The airway response to challenge tests can be meas'ured in several ways, spirometry, body plethysmography and flow volume measurements being the most common. These differ in terms of reproducibility, sensitivity, and ease of performance, so that each test is appropriate for different types of study. The ways in which the response or doseresponse relationship is analysed are equally diverse. One method suggested by Orehek et $a l^{5}$ is to describe the dose of stimulus needed to initiate bronchoconstriction as "sensitivity" and the slope of the subsequent dose-response relationship as "reactivity". "Reactivity" used in this way should not be confused with the use of bronchial reactivity in a more general sense as in the title of this article.

Despite the large number of factors affecting the stimulus-response relationship, reproducible responses can be obtained in stable patients if identical techniques are used both to administer the challenge and measure the response. ${ }^{6-8}$ Account needs to be taken of the refractory period after any test; this is well recognised up to four hours after exercise but may also occur to a lesser extent after histamine inhalation. ${ }^{9}$ Bronchial challenge tests are usually safe when carried out with careful supervision and selection of patients, although all challenge tests must carry some risk, particularly in inexperienced hands. Greater care is needed for patients with more labile airways obstruction and patients with an $\mathrm{FEV}_{1}$ of less than $50 \%$ predicted should not normally be challenged.

Having established that reproducible bronchial reactivity tests can be obtained, the more difficult question of interpretation needs to be considered. There is an assumption underlying these tests that they are detecting and measuring changes in the responsiveness of bronchial smooth muscle to pharma- 
cological and physiological stimuli. This can be questioned both from circumstantial evidence and for theoretical reasons. An interesting pattern has emerged from recent studies of bronchial reactivitynamely, that bronchodilatation is almost invariably associated with reduced bronchial reactivity, irrespective of whether the bronchodilatation occurs spontaneously, ${ }^{10} 11$ or after drugs ${ }^{12-14}$ and conversely bronchoconstriction is usually associated with increased bronchial reactivity. ${ }^{1516}$ Furthermore, bronchodilating and bronchoconstricting agents have the same effect on bronchial reactivity even when they produce no demonstrable bronchodilatation and bronchoconstriction. ${ }^{16-21}$ This latter situation can arise when there is no further capacity to change airway calibre, for example, when maximal bronchodilatation has occurred, or alternatively, it may occur after a very small dose of drug, when the ability to detect change in airway calibre depends on the detection limits of the test measuring the response. In this situation, the drug is more likely to be causing no detectable change in airway calibre rather than no change. This issue of Thorax contains two further illustrations of this relationship between bronchodilating and bronchoconstricting agents and changes in bronchial reactivity. Fenoterol caused bronchodilatation and reduced bronchial reactivity in the study by Salome et al, ${ }^{22}$ while $\mathrm{PGF}_{2} a$, a bronchoconstricting agent, caused increased bronchial reactivity in the study by Walters et al. ${ }^{23}$

From the theoretical point of view, bronchial reactivity tests are unlikely to reflect bronchial smooth muscle responsiveness accurately because, for various reasons, the response will be influenced by the degree of airways obstruction. Firstly, with an inhalation challenge in patients with severe airways obstruction, more stimulus is deposited centrally than peripherally. ${ }^{24}$ This would cause an overestimation of bronchial reactivity if the stimulus was acting centrally, or the reverse if it was acting peripherally. Secondly, the measurement of flow or resistance is influenced by the degree of airways obstruction, as discussed by Benson. ${ }^{25}$ The same absolute reduction in circumference-that is, the same absolute amount of smooth muscle shorteningwill cause a proportionally greater reduction in radius ( $r$ ) in subjects with airways obstruction than in normal subjects. Consequently, these patients will show a much greater reduction in flow since, with laminar flow, flow is proportional to $r^{4}$. Thirdly, the partitioning of resistance is important, ${ }^{25}$ since the major site of resistance is in large airways in normal subjects and in smaller airways in patients with airways obstruction. ${ }^{26}$ Thus, a stimulus causing a twofold increase in peripheral airways resistance will have a much larger effect in the patient, where the peripheral contribution to total airways resistance is predominant. Thus, for three different reasons, neither the absolute nor percentage change in flow or resistance will accurately reflect changes in bronchial reactivity. Subjects with initial airway narrowing would be expected for, geometric reasons alone, to have a larger response to a given stimulus. Other factors, such as changing lung volume and nonlaminar flow will further distort the stinulusresponse relationship.

These theoretical predictions have been confirmed in practice, since patients with poor pulmonary function have in general shown a greater response to exercise or an inhalation challenge. 681527 It has usually been less apparent when change in pulmonary function in individual subjects has been correlated with change in bronchial reactivity. ${ }^{11} 16-18$ Although it has sometimes been argued from this failure to find a correlation that geometrical factors are unimportant, the failure can be equally well explained by the small number of subjects in many studies, the relatively small changes in pulmonary function in individual subjects, the imperfections of measurements such as $\mathrm{FEV}_{1}$ or airway resistance as a measure of airway calibre, and the complexity of the relationship between these measurements and their effect on bronchial reactivity. This point is demonstrated in the study by Juniper $e a^{2} l^{28}$ in this issue, where patients with the greatest response to histamine and methacholine (group 4) had the lowest initial $F_{E V}$ values. Although percentage predicted $F E_{1}$ values for groups 2 and 4 did not differ significantly the difference in mean absolute values between $2 \cdot 1$ and 3.2 litres must reflect differences in airway calibre and the distribution of resistance. The difficulty in this situation is not in determining whether airway calibre is having any effect but in deciding how much of the measured change in bronchial reactivity is a true difference in bronchial muscle responsiveness and how much can be accounted for by geometric factors.

These problems are overcome to some extent when patients with similar $\mathrm{FEV}_{1}$ or airways resistance values are compared, as with groups 1 and 2 in Juniper's study where the different responses to histamine and methacholine are more likely to reflect a true difference in reactivity. When patients with similar specific airway conductance values were studied elsewhere, ${ }^{29}$ those with a clinical diagnosis of asthma showed more bronchoconstriction after histamine and more bronchodilatation after isoprenaline than those considered to have chronic bronchitis. Increased bronchial reactivity has also been demonstrated in patients with normal values for $\mathrm{FEV}_{1}$ or airway resistance, including patients with mild asthma, ${ }^{6}$ normal subjects after an upper 
respiratory tract infection, ${ }^{6} 17$ and atopic subjects. ${ }^{30}$ Normal values for a global measurement like FEV 1 or airway resistance do not necessarily mean that peripheral airway function is normal, but differences in airway geometry are unlikely to explain all the observed changes in bronchial reactivity.

In the study by Salome et al in this issue, ${ }^{22}$ oral and inhaled fenoterol caused a similar increase in $\mathrm{FEV}_{1}$ in patients with mild asthma. Oral fenoterol produced no significant change in the response to methacholine and histamine, while inhaled fenoterol caused a large decrease in the "sensitivity" to both, but no change in "reactivity"- -that is, a parallel change in the stimulus-response relationship. As the authors suggest, the difference between oral and inhaled fenoterol is probably caused by differences in drug concentration on airway smooth muscle which might not be reflected in the $\mathrm{FEV}_{1}$ since this was close to $100 \%$ predicted after both forms of administration. These changes would be anticipated from a theoretical model of the stimulus-response relationship of bronchial smooth muscle (figure). Bronchial

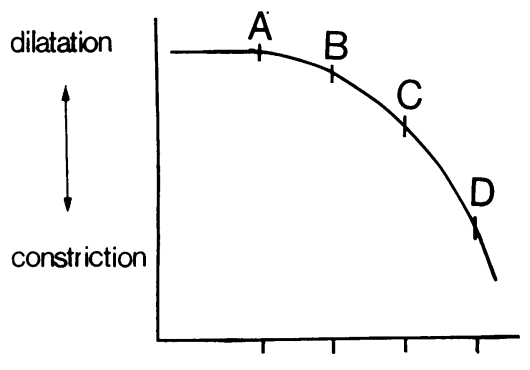

stimulus

Figure Hypothetical stimulus-response relationship for bronchial smooth muscle. Taken from Benson. ${ }^{25}$

muscle from asthmatic patients is presumably on the steeper part of the stimulus-response curve B or C and would produce a large response to the same constrictor stimulus, B-C or C-D. The bronchodilator response to drugs such as fenoterol or atropine may be associated with detectable bronchodilatation (C-B) or not (B-A). The greater local drug concentrations in the airways after inhaled fenoterol could cause similar degrees of bronchodilation, C-A compared with oral fenoterol C-B, though the effect of a subsequent constrictor simulus would be different, A-B versus B-C.

This simple model does not explain whether patients with asthma are on the steeper part of the stimulus-response curve because of an inherent abnormality in bronchial smooth muscle or because normal smooth muscle is being stimulated excessively by hormones, mediators, or the vagus. The model does fit many of the observed interactions of drugs on airways and their effects on bronchial reactivity, including the studies by Salome et al and Walters $e t$ al already mentioned..$^{22} 23$ It provides a further explanation for changes in reactivity after bronchodilating and bronchoconstricting agents in the absence of detectable changes in airway calibre. It will also be apparent that a change in the response to a given stimulus could be the results of a change in baseline, for example, from $\mathrm{B}$ to $\mathrm{C}$, a parallel change in the dose-response curve, or a change in the shape of the dose-response curve. Analysing the doseresponse curve in terms of "reactivity" and "sensitivity"5 should help to separate the latter two, although it is of course the translation from this hypothetical stimulus-response curve to the in vivo dose-response curve where inaccuracies in measuring stimulus dose and difficulties in correcting the response for the degree of airways obstruction cause problems. Nevertheless, this type of analysis would appear to provide most information and may help to explain how pharmaceutical agents affect bronchial reactivity.

Another interesting point on interpretation emerges from the study by Salome et al. ${ }^{22}$ Their results with fenoterol are very similar to previous studies with atropine which also reduces the sensitivity of asthmatic patients to histamine. ${ }^{12}$ The results with atropine have been widely interpreted as evidence that histamine is producing a reflex action through the vagus 79 in addition to its direct effect on smooth muscle. If the same effect occurs with a betaagonist which is presumably not acting on the vagus but is causing bronchial smooth muscle relaxation, is it not equally possible that the reduced sensitivity to histamine and other stimuli after atropine is also a non-specific effect of bronchodilatation?

In view of the problems in interpreting bronchial reactivity tests it is not surprising that there are considerable differences in the way in which these tests are used in the diagnosis, assessment, and management of patients with asthma. Practice in the United Kingdom is usually fairly conservative with exercise tests being reserved largely for patients with intermittent symptoms and normal pulmonary function in the clinic, or to assess disability from exercise and response to treatment. Chalienge tests are rarely done in patients with a clear history of asthma and demonstrable bronchodilatation after a beta-agonist. Elsewhere however the measurement of bronchial reactivity is regarded "as essential to the diagnosis and management of asthma as the glucose tolerance test was to diabetes", 31 and the American 
Thoracic Society includes bronchial hyperreactivity in its definition of asthma. ${ }^{32}$ From Canada, Juniper et $a l^{28}$ suggest that a histamine challenge test might be used to determine optimal treatment for patients with mild asthma, though the need to ensure that patients were stable for six weeks makes it rather impractical for routine management.

Thus, in the present state of our understanding of bronchial reactivity and bronchial reactivity testing the measurement in man should be regarded as a very imperfect reflection of any change in smooth muscle responsiveness, despite the improved techniques for assessment. Care is needed in the interpretation of these tests for a variety of reasons and particularly in the interpretation of the effects of bronchoconstricting and bronchodilating agents. In practice these usually cause an increase and decrease respectively in bronchial reactivity even when no change in airway calibre can be detected, suggesting that many of the changes previously attributed to specific pharmacological actions are in fact non-specific. The challenge now is to design studies which will help to dissociate the effects of airway geometry from true pharmacological effects, and to try to determine which pharmacological actions are specific and which nonspecific.

ANNE E TATTERSFIELD

Faculty of Medicine

University of Southampton

Southampton General Hospital

Southampton

\section{References}

${ }^{1}$ Ryan G, Dolovich MB, Obminski G et al. Standardization of inhalation provocation tests: influence of nebuliser output, particle size and method of inhalation. J Allergy Clin Immunol $1981 ; 67: 156-61$.

${ }^{2}$ Newman SP, Pavia D, Clarke SW. How should a pressurised B-adrenergic bronchodilator be inhaled. Eur $J$ Respir Dis 1981;62:3-21.

${ }^{3}$ Blackwell EW, Briant RH, Conolly ME, Davies DS, Dollery CT. Metabolism of isoprenaline after aerosol and direct intrabronchial administration in man and dog. Br J Pharmacol 1974;50:587-91.

${ }^{4}$ Newman SP, Pavia D, Moren F, Sheahan NF, Clarke SW. Deposition of pressurised aerosols in the human respiratory tract. Thorax $1981 ; 36: 52-5$.

"Orehek J, Gayrard P, Smith AP, Grimaud C, Charpin J. Airway response to carbachol in normal and asthmatic subjects. Distinction between bronchial sensitivity and reactivity. Am Rev Respir Dis 1977;115:937-43.

${ }^{6}$ Parker CD, Bilbo RE, Reed CE. Methacholine aerosol as test for bronchial asthma. Arch Intern Med 1965;115: 452-8.

? Juniper EF, Frith PA, Dunnett C, Cockcroft DW, Hargreave FE. Reproducibility and comparison of responses to inhaled histamine and methacholine. Thorax 1978;33:705-10.

${ }^{8}$ Haynes RL, Ingram RH, McFadden ER Jr. An assessment of the pulmonary response to exercise in asthma and an analysis of the factors influencing it. Am Rev Respir Dis 1976;114:739-52.

${ }^{9}$ Schoeffel RE, Anderson SD, Gillam I, Lindsay DA. Multiple exercise and histamine challenge in asthmatic patients. Thorax 1980;35:164-70.

${ }^{10}$ Orehek J, Gayrard P. Les tests de provocation bronchique non-specifiques dans l'asthme. Bull Eur Physiopath Respir 1976;12:565-98.

"Geubelle F, Barlee-Harmans G, Leclercq-Foucart J. Hyperreactivity of the bronchial tree to histamine in asthmatic children and its variations. Bull Physiopathol Respir 1971;7:839-40.

12 Cockcroft DW, Killian DN, Mellon JJA, Hargreave FE. Protective effect of drugs on histamine-induced asthma. Thorax 1977;32:429-37.

${ }^{13}$ Booj-Noord H, Quanjier PH, deVries K. Protective effect of Berotec in provocation tests using inhalation of specific allergens and histamine. Int J Clin Pharmacol $1972: 4: 69-72$

${ }^{14}$ Hartley JPR, Nogrady SG. Effect of an inhaled antihistamine on exercise-induced asthma. Thorax 1980;35: 675-9

${ }^{15}$ Orehek J, Massari JP. Gayrard P, Grimaud C, Charpin J. Effect of short-term low level nitrogen dioxide exposure on bronchial sensitivity of asthmatic patients. J Clin Invest 1976;57:301-7.

${ }^{16}$ Cockcroft DW, Ruffin RE, Dolovich J, Hargreave FE. Allergen-induced increase in non-allergic bronchial reactivity. Clin Allergy 1977;7:503-13.

17 Empey DW, Laitinen LA, Jacobs L, Gold WM, Nadel JA. Mechanisms of bronchial hyperreactivity in normal subjects after upper respiratory tract infection. $A m R e v$ Respir Dis 1976;113:131-9.

${ }^{18}$ Holtzman MJ, Cunningham JH, Sheller JR, Irsigler GB, Nadel JA, Boushey HA. Effect of ozone on bronchial reactivity in atopic and non atopic subjects. $A m R e v$ Respir Dis 1979;120:1059-67.

19 Golden JA, Nadel JA, Boushey HA. Bronchial hyperirritability in healthy subjects after exposure to ozone. Am Rev Respir Dis 1978;118:287-94.

${ }^{20}$ Cockcroft DW, Cotton DJ, Mink JT. Non-specific bronchial hyperreactivity after exposure to western red cedar. Am Rev Respir Dis 1979;119:505-10.

${ }^{21}$ Hartley JPR, Davies BH. Cholinergic blockade in the prevention of exercise-induced asthma. Thorax 1980;35: 680-5.

${ }^{22}$ Salome CM, Schoeffel RE, Woolcock AJ. Effect of aerosol and oral fenoterol on histamine and methacholine challenge in asthmatics. Thorax 1981;36:580-4.

${ }^{23}$ Walters EH, Parrish RW, Bevan C, Smith AP. Induction of bronchial hypersensitivity: evidence for a role for prostaglandins. Thorax 1981;36:571-4.

${ }^{24}$ Pavia D, Thomson ML, Clarke SW, Shannon HS. Effect o of lung function and mode of inhalation on penetration of aerosol into the human lung. Thorax 1977;32:194-7.

${ }^{25}$ Benson MK. Bronchial hyperreactivity. Br J Dis Chest $1975 ; 69: 227-39$.

${ }^{26}$ Pride NB. The assessment of airflow obstruction. Role of measurement of airways resistance and of tests of forced expiration. Br J Dis Chest 1971;65:135-69.

27 Makino S. Clinical significance of bronchial sensitivity to acetylcholine and histamine in bronchial asthma. $J$ Allergy 1966;38:127-41.

28 Juniper EF, Frith PA, Hargreave FE. Airway responsiveness to histamine and methacholine: relationship to minimum treatment to control symptoms of asthma. Thorax $1981 ; 36: 575-9$.

29 Benson MK. Bronchial responsiveness to inhaled histamine and isoprenaline in patients with airway obstruction. Thorax 1978;33:211-3. 
${ }^{30}$ Stevens WJ, Vermeire PA. Bronchial responsiveness to histamine and allergen in patients with asthma rhinitis and cough. Eur J Respir Dis 1980;61:203-12.

${ }^{31}$ Woolcock A. Airway reactivity-mechanisms and clinical relevance. Ontario, Canada: Astra, 1980.
${ }^{32}$ American Thoracic Society. Chronic bronchitis, asthma and pulmonary emphysema. A statement by the committee on diagnostic standards for non-tuberculous respiratory disease. Am Rev Respir Dis 1962;82:762-8.

\section{European}

Society for

Clinical

Respiratory

Physiology
A meeting on Hypoxia will be held in Palermo, Sicily from 5 to 8 October 1982. Further information may be obtained from Dr DW Empey, Secretary General, The London Hospital, Whitechapel, London E1 1BB 